\title{
CARACTERÍSTICAS, USO AGRÍCOLA ATUAL E POTENCIAL DAS VÁRZEAS NO ESTADO DO AMAZONAS, BRASIL.'
}

\author{
Manoel da Silva CRAVO², José Jackson B. N. XAVIER', Miguel Costa DIAS ${ }^{3}$, \\ João Ferdinando BARRETO ${ }^{3}$
}

RESUMO - Neste trabalho procura-se destacar as principais caracteristicas das várzeas que ocorrem no Estado do Amazonas c suas influências sobre as atividades agrícolas, tomando-se como base trabalhos desenvolvidos nesse ecossistema. No Amazonas sào diferenciados dois grandes ccossistemas: "terra firme" e "várzeas". Terra firme é um termo genérico, usado na Amazônia, para designar locais que nào sofrem inundações provocadas pelos rios. $\mathrm{O}$ termo "Várzea" é utilizado para designar áreas situadas às margens dos rios de água "barrenta" ou "branca", sujeitas a inundaçòes periódicas causadas pelos rios. Essas cnchentes contribuem anualmente com novos depósitos de sedimentos, oferecendo uma camada de solo novo e fértil, às margens do rio Solimões e aflucntes. Nas margens dos ríos de água clara ou preta, não hả formação de várzeas. As que se formam às margens desses rios sào por influência dos rios de água barrenta e são menos férteis do que aquelas quc ocorrem às margens desses rios. As várzeas, por apresentarem solos de fertilidade mais elevada, sào intensivamente utilizados para fins agrícolas, no periodo em que não estão inundadas. As produtividades das culturas nesse ecossistema são mais elevadas do que nas terras firmes mas, o cultivo continuo, sem inundação dos rios, leva a decair essa produtividade. Um dos principais fatores limitantes para o uso continuo da várzca é a infestação por ervas daninhas. A distância dos mercados consumidores é um fator que deve ser considerado, quando da definição da utilização das várzeas, para fins agrícolas.

Palavras Chaves: Região Amazônica; Várzeas Amazônicas; Regime de Enchente de Várzcas; Solos de Várzeas.

Characteristics, Potential and Actual Agricultural Use of Floodplains in the Amazonas State, Brazil.

SUMMARY - In this work we try to stand out the main characteristics of the floodplains that occur in the Brazilian State of Amazonas, and its influences on the agricultural activities, based on works developed in that ecosystem. In Amazonas State two great ecosystems are differentiated: "Terra Firme" (highland) and "Várzeas" (floodplain). "Terra Firme" is a generic term, used to designate local that don't suffer floods provoked by the rivers. The term "Várzea" designate areas at the margins of the rivers of "loamy" or "white" water , subject to periodic floods caused by those rivers. By means of the floods of the "Várzeas" new contributions of sediments are registered, particularly to the margins of the rivers of "white" water as the Solimones river. In the margins of the rivers of clear and black water, there is not "Varzeas" formation. The ones that are formed are by influence of the rivers of "white" water, and they are less fertile. The "Várzeas", due to present soils of higher fertility, are intensively used for agricultural purpose, in the period that are not flooded. The productivity of the crops in the "Varzeas" are higher than that in "Terra Firme" but, in the continuous cultivation, without flood of the rivers, the productivity of crops decay. One of the main factors that limits the continuous use of the "Várzea" areas is the high occurrence of weeds. The distance of the consuming markets is a factor that should be considered, when of the planing of use of the "Várzeas" for agricultural purpose.

Key-words: Amazon region; Regime of Flooding of "Varzcas"; Soils of "Varzeas".

'Parte do traba!ho apresentado no Workshop sobre Uso Atual e Potencial das Várzeas Amazónicas realizado em Boa Vista (RR) em 1996.

${ }^{2}$ Pesquisador da Embrapa Aunazônia Oriental, Trav. Dr. Enças Pinheiro, s/no, Caixa Postal, 48, 66095-100-Belen - Para. E-mail cravorexpen.com.br

Pesquísadores da Emibrapa Amazónia Ocidental. Rodovia AM 010, Km 28 s/no, Caixa Postal 319. CEP 69.01\}-970 - Manaus - Amazonas.

ACTA AMAZONICA 32(3): 35l-365. 2002. 


\section{Introdução}

Os principais solos do Estado do Amazonas estão localizados em dois grandes ecossistemas: "terra firme" e "várzeas". Terra firme é um termo genérico, usado na região Amazônica, para designar locais que não sofrem influência das inundações provocadas pelos rios. Esse ecossistema cobre a maior parte do Estado, sendo os principais solos classificados como Latossolos e Podzólicos caracterizados, com raras exceções, como de baixa fertilidade e elevada acidez.

O termo "Várzea" é utilizado para designar áreas sujeitas a inundações periódicas causadas pelas enchentes dos rios. Essas áreas estão distribuídas nas margens dos rios de água "barrenta" e estão sujeitas a inundações anuais, as quais contribuem com novos depósitos de sedimentos, oferecendo uma camada de solo novo e fértil para a agricultura (Cravo \& Smyth, 1991a). Desta forma, os solos das várzeas são formados pela deposição anual desses sedimentos, ricos em minerais, derivados de rochas calcárias da Cordilheira dos Andes, que estão em suspensão nas "águas barrentas" e, devido a isso, são caracterizados, em sua maior parte, por apresentarem alta fertilidade e baixa acidez (Sioli, 1957).

O Estado do Amazonas possui cerca de 24,8 milhões de hectares de solos de várzea (Brasil, 1979), distribuídos ao longo dos seus inúmeros cursos d'água, notadamente às margens dos Rios Amazonas/
Solimões e seus principais afluentes. Essas áreas, em sua grande maioria, são consideradas aptas para a prática agricola, principalmente com culturas anuais, semi-perenes e pastagens (Corrêa \& Bastos, 1982).

\section{Características das Várzeas do Estado do Amazonas}

\section{Regime de Enchente dos Rios e Caracterização dos Ambientes de Várzeas}

O regime de enchentes dos rios no Estado do Amazonas é anual e as cotas mais elevadas são atingidas entre os meses de abril a julho (Fig. 1). Ainda assim, essas terras são anualmente cultivadas durante oito meses e, em muitos anos, a enchente não atinge as várzeas altas, prolongando-se o período de cultivo. Esse prolongamento ocorre quando a cota de enchente, medida no porto de Manaus, não ultrapassa os 27 metros, considerando-se essa cota como nível crítico para o uso agrícola das várzeas altas do Rio Solimões, próximas de Manaus (Cravo \& Smyth, 1991a).

São diferenciados dois tipos de várzeas, de acordo com sua posição em relação à calha do rio: várzeas altas, também chamadas de "restinga", que são as partes do terreno mais elevadas, localizadas próximo às margens dos cursos d'água e, várzeas baixas, situadas mais afastado das margens dos rios e sujeitas à inundações mais prolongadas. As primeiras, devido a vegetação de restinga, recebem o depósito de sedimentos maiores que estão em 


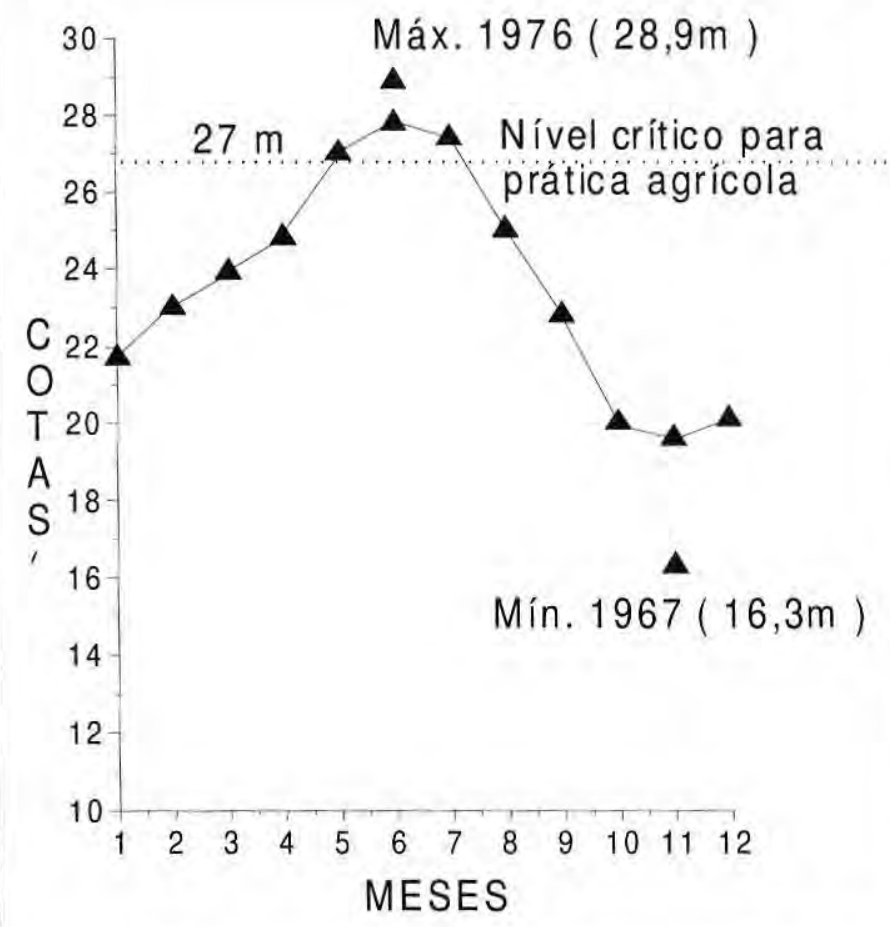

Figura 1. Médias mensais das cotas de enchente do Rio Negro, no porto de Manaus - Periodo de 1966 - 1989 ( Fonte: Cravo \& Smyth, 1991a)

suspensão nas águas e, por isso, apresentam melhor drenagem e são cultivadas mais intensivamente com culturas anuais e semi-perenes. Já as várzeas baixas, nício das enchentes recebem as águas do igapó, pobres em sedimentos e, devido a isso, apresentam problemas de drenagem, sendo utilizadas principalmente com pastagens nativas e, raramente, com culturas anuais (Cravo \& Smyth, 1991b). Além desses dois tipos de várzeas, ainda existe um terceiro denominado, principalmente na região do Baixo Amazonas, como "praias" que é formado pelo desmoronamento de barrancos, situados às margens dos rios, sendo expostas à medida que o rio vai secando. Essas áreas são utilizadas intensivamente para cultivo de ciclo curto (olerícolas, feijão caupi ou "de praia", milho, juta e outras) e pastagem nativa.

\section{Efeitos da Qualidade das Águas nas Características Químicas dos Solos e Sobre a Produtividade das Culturas}

As águas dos rios, na Amazônia, ditam o periodo de aproveitamento agrícola das várzeas. Por outro lado, as qualidades dessas águas ditam as 
características químicas dos solos dessas várzeas e, consequentemente, a produtividade das culturas.

Os principais solos encontrados nas áreas de várzea pertencem à classe dos Entisols na classificação americana, os quais correspondem aos Aluviais, Gley Húmico, Gley Pouco Húmico e Plintossolos, na classificação brasileira (Cochrane \& Sánchez, 1982; Corrêa \& Bastos, 1982), podendo ser eutróficos ou distróficos, dependendo de sua localização e do tipo de água que os inundam.

Deve ser ressaltado que rios de água "preta" (como o rio Negro) ou "clara" (como o Tapajós) não formam várzeas. As que eventualmente ocorrem, nas margens de rios ou paranás de água preta ou clara, são formadas por influência da invasão das águas barrentas dos rios maiores, por ocasião das grandes enchentes. Os solos dessas várzeas, assim formadas, sofrem grande influência das águas pretas ou claras, tornando-os ácidos e de baixa fertilidade. Análises realizadas em amostras de solos dessas várzeas, de diversos municípios do Estado do Amazonas, revelaram diferenças marcantes, principalmente nos teores de $\mathrm{Ca}, \mathrm{Mg}, \mathrm{Al}, \mathrm{K}$ e $\mathrm{P}$ (Embrapa, 1984). Nota-se, por exemplo (Tab. 1), que os teores desses elementos em amostras de solo dos municípios de Barreirinha e Manaquiri, são bem inferiores aos observados em outros municípios, sem influência de água clara ou preta (Manacapuru e Parintins). Essas caracteristicas exerceram grande influência sobre a produtividade de feijão caupi, cultivado no município de Manaquiri (Dias, dados não publicados). Conforme pode ser visto na Tabela 2 , as produtividades de grãos, obtidas em áreas de várzeas de rio de água preta, com duas variedades de feijão caupi, foram $50 \%$ inferiores às obtidas em várzeas de rios de água barrenta.

Apesar de apresentarem boa fertilidade natural, a maioria dos solos das várzeas dos rios de água barrenta do Estado do Amazonas é potencialmente deficiente em nitrogênio. Os teores de Carbono orgânico (C) e Nitrogênio total $(\mathrm{N})$, em seus solos, são relativamente baixos. Resultados de análises dos solos das várzeas do Paraná dos Ramos (Barreirinha), apresentaram teores de C orgânico na faixa de 0.14 a $2,33 \%$ e teores de $\mathrm{N}$ total na faixa de 0,05 a $0,19 \%$ (Corrêa \& Bastos, 1982). Embora os valores da relação $\mathrm{C} / \mathrm{N}$ (faixa de 3 a 28) apresentem indicios de boa capacidade de mineralização do $\mathrm{N}$ orgânico, os baixos teores de $\mathrm{N}$ total sugerem que as reservas naturais de $\mathrm{N}$ no solo são limitadas (Melgar et al., 1992).

Estudos realizados em várzea alta do Rio Solimões (Embrapa, 1981; 1982; 1984) mostraram evidências de deficiências de $\mathrm{N}$, quando a várzea é cultivada em anos consecutivos, sem haver inundação da área. Isso está evidenciado nos dados da Tabela 3 pois, no segundo ano de cultivo sem inundação, as produtividades de milho e arroz obtidas foram muito baixas e as plantas mostravam-se com visiveis sintomas de deficiência de nitrogênio. Essas observações são reforçadas 
Tabela 1. Valores médios, máximos e mínimos de algumas propriedades químicas dos solos de várzea, em 6 municipios do Estado do Amazonas.

\begin{tabular}{|c|c|c|c|c|c|c|c|c|c|}
\hline Município & $\begin{array}{l}\text { Número de } \\
\text { amostras }\end{array}$ & Valores & $\mathrm{pH}$ & $\mathrm{Ca}$ & $\mathrm{Mg}$ & Al & $\begin{array}{c}\text { Saturação } \\
\text { de Al }\end{array}$ & K & $P$ \\
\hline & & & $(\mathrm{H} 2 \mathrm{O})$ & \multicolumn{3}{|c|}{ cmolc dm-3 } & $\%$ & \multicolumn{2}{|c|}{$\mathrm{mg} \cdot \mathrm{kg}-1$} \\
\hline & & Médio & 4.7 & 3.7 & 2.6 & 2.5 & 27 & 92 & 32 \\
\hline \multirow[t]{3}{*}{ Barreirinha } & 27 & Máximo & 5.5 & 5.9 & 5.0 & 5.5 & 56 & 308 & 80 \\
\hline & & Mínimo & 4.3 & 2.2 & 1.5 & 0.1 & 1 & 42 & 2 \\
\hline & & Médio & 5.9 & 9.4 & 3.5 & 0.4 & 2 & 139 & 92 \\
\hline \multirow[t]{3}{*}{ Careiro } & 6 & Máximo & 6.6 & 11.5 & 4.5 & 0.9 & 6 & 290 & 279 \\
\hline & & Mínimo & 5.3 & 6.0 & 2.8 & 0.0 & 0 & 29 & 33 \\
\hline & & Médio & 5.2 & 9.7 & 3.0 & 0.6 & 5 & 108 & 84 \\
\hline \multirow[t]{3}{*}{ Manacapuru } & 26 & Máximo & 5.9 & 13.8 & 4.7 & 2.5 & 18 & 180 & 650 \\
\hline & & Mínimo & 4.4 & 7.0 & 0.5 & 0.1 & 1 & 50 & 11 \\
\hline & & Médio & 4.7 & 9.0 & 2.3 & 2.9 & 23 & 91 & 39 \\
\hline \multirow[t]{3}{*}{ Manaquiri } & 18 & Máximo & 5.8 & 14.0 & 4.2 & 8.4 & 73 & 218 & 100 \\
\hline & & Mínimo & 4.0 & 2.2 & 0.2 & 0.1 & 1 & 25 & 3 \\
\hline & & Médio & 4.9 & 5.1 & 3.0 & 1.9 & 20 & 206 & 61 \\
\hline \multirow[t]{3}{*}{ Parintins } & 6 & Máximo & 5.6 & 7.3 & 4.3 & 3.3 & 31 & 288 & 80 \\
\hline & & Mínimo & 4.1 & 3.2 & 2.6 & 0.3 & 3 & 102 & 33 \\
\hline & & Médio & 5.2 & 6.7 & 2.8 & 1,1 & 10 & 54 & 74 \\
\hline \multirow[t]{2}{*}{ Urucará } & 2 & Máximo & 5.4 & 8.5 & 4.3 & 1.8 & 16 & 86 & 100 \\
\hline & & Mínimo & 5.0 & 4.9 & 1.3 & 0.4 & 4 & 23 & 48 \\
\hline
\end{tabular}

Fonte: Embrapa (1984)

Tabela 2. Produtividade de feijão caupi em várzeas de rios de água barrenta e preta CULTIVARES

\begin{tabular}{|c|c|c|c|c|}
\hline \multirow[t]{2}{*}{ Município } & \multicolumn{2}{|c|}{ IPEAN V - 69} & \multicolumn{2}{|c|}{ MANAUS } \\
\hline & Água barrenta & Água preta & Água barrenta & Água preta \\
\hline & \multicolumn{4}{|c|}{ 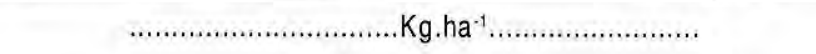 } \\
\hline Manaquiri & - & 663 & - & 607 \\
\hline Manacapuru & 1.440 & - & 1.360 & - \\
\hline Barreirinha & 1.320 & - & 1.311 & - \\
\hline Parintins & 1.122 & . & 1.323 & - \\
\hline Média & 1.294 & 663 & 1.331 & 607 \\
\hline
\end{tabular}

Fonte: Dias (dados não publicados). 
Tabela 3 - Efeitos da inundação das várzeas sobre a produtividade de milho e arroz.

\begin{tabular}{|c|c|c|}
\hline Cultura & $1^{0} \mathrm{Ano}(\mathrm{C} /$ Inundação) & $2^{0}$ Ano (S/ inundaçāo) \\
\hline & \multicolumn{2}{|c|}{ …............................ tha } \\
\hline Arroz & 4,0 & 2,0 \\
\hline Milho & 4,7 & 2,0 \\
\hline
\end{tabular}

Fonte: Embrapa (1981)

pelas respostas positivas de milho e arroz, ao nitrogênio, encontradas por Melgar et. al. (1992) nas várzeas do Solimões.

Da mesma forma, o tempo de cultivo da mesma área de várzea, sem sofrer inundação entre um cultivo e outro, tem influência sobre a produtividade das culturas. Arroz e milho foram plantados em áreas que vinham sendo cultivadas por vários anos, sem inundação e em áreas recém desmatadas da floresta de várzea. $\mathrm{Na}$ área nova a produtividade alcançada foi aproximadamente o dobro da obtida na área de cultivo contínuo (Tab. 4). Na área de cultivo contínuo as plantas de milho e arroz se mostravam com sintomas típicos de deficiência de nitrogênio, com espigas e panículas, respectivamente, pequenas e mal granadas (Melgar et. al, 1992).

Tais evidências ficam demonstradas, principalmente ao se considerar que resultados de análises do solo realizadas em anos subsequentes, sem inundação da área, mostraram decréscimo, principalmente nos teores de N (Tab. 5), o que pode estar contribuindo para a diminuição das produtividades do milho e arroz, vistas na Tabela 4, concordando com as observações de Melgar et. al., (1992).

\section{Uso Atual das Várzeas do Amazonas}

As principais utilizações agrícolas das várzeas do Estado do Amazonas são com culturas anuais e pecuária extensiva, com aproveitamento das pastagens nativas. Em menor escala as várzeas são utilizadas para fruticultura, principalmente as semi-perenes, como o mamão, maracujá e banana, próximo aos grandes centros consumidores. Em passado recente o cultivo de malva $\mathrm{e}$ juta era muito intenso nas várzeas do Amazonas. Atualmente, devido às exigências do mercado internacional por embalagens de fibras naturais, está havendo incentivo governamental para a retomada dessa atividade no Estado.

Outra atividade muito intensa nas várzeas é a pesca nos lagos, por ocasião da descida das águas, constituindo-se em uma das principais fontes de pescado para os mercados das sedes dos municípios e de aumento da renda dos ribeirinhos.

Dentre as culturas anuais, exploradas nas várzeas, destacam-se a mandioca para farinha e as olerícolas, tais como: alface, repolho, couve, pepino, feijão vagem, feijão de metro, 
Tabela 4. Efeito do cultivo contínuo de áreas de várzea, sem sofrer inundação, sobre a produtividade de arroz e milho.

\begin{tabular}{|c|c|c|}
\hline Cultura & Ảrea recém desbravada & Área de cultivo contínuo \\
\hline & …-1, & 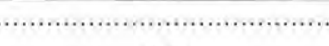 \\
\hline Arroz & 4,4 & 2,7 \\
\hline Milho* & 3,7 & 2,4 \\
\hline
\end{tabular}

Fonte: Embrapa (1984)

* variedade de polinização aberta

Tabela 5. Resultados de análise do solo, em anos consecutivos, sem inundação da área de várzea.

\begin{tabular}{|c|c|c|c|c|c|c|c|c|c|}
\hline \multirow{3}{*}{ Ano } & \multicolumn{9}{|c|}{ Parâmetros Analisados } \\
\hline & $\mathrm{pH}$ & $P$ & $\mathrm{Ca}$ & $\mathrm{Mg}$ & $\mathrm{K}$ & Al & Sat, Al & C & $N$ \\
\hline & $\left(\mathrm{H}_{2} \mathrm{O}\right)$ & $\mathrm{mg} \cdot \mathrm{kg}^{-1}$ & ....... & $\ldots \mathrm{cn}$ & $\mathrm{m}^{3} \ldots$ & ........ & ..... & $\ldots \%$ & $\ldots \ldots$. \\
\hline 1 & 5,6 & 117 & 14,9 & 2,9 & 0,34 & 0,19 & 1,0 & 1,00 & 0,11 \\
\hline 2 & 6,1 & 114 & 8,0 & 1,7 & 0,31 & 0,23 & 2,2 & 0,82 & 0,08 \\
\hline
\end{tabular}

Fonte: Embrapa (dados nåo publicados)

feijão caupi, berinjela, quiabo, maxixe, coentro, salsa, cebolinha, abóbora, cará, melancia, macaxeira, batata doce e milho verde. $\mathrm{O}$ milho para grãos, o feijão caupi e o arroz são cultivados, principalmente para auto consumo, nas várzeas mais distantes dos grandes centros.

Destacam-se, entre os frutos produzidos nas várzeas, a banana (de diversas variedades), mamão, maracujá e açai, contribuindo grandemente para o abastecimento dos mercados das principais cidades do Estado.

Nos pomares existentes nas várzeas, entretanto, tem sido observados alguns sintomas de deficiências nutricionais e problemas de doenças. No mamão, normalmente se observa sintomas de deficiência de boro, causando a deformação dos frutos (sintoma conhecido como "cara de gato"), diminuindo o valor comercial do fruto. Nos maracujazeiros e coqueiros, a deficiência de nitrogênio e, nas bananeiras, a deficiência de nitrogênio e ataque de doenças. Mesmo assim, tem sido obtidos bons rendimentos dessas culturas nesse ecossistema.

Um problema que é comum em todas as atividades agricolas nas várzeas é a infestação por plantas daninhas, principalmente em áreas de cultivo contínuo. Devido a isso, alguns agricultores vêm adotando o uso de herbicidas, sem a menor orientação sobre dosagens, sobre as necessidades de sua proteção durante as aplicações e, sobre os possiveis efeitos danosos desses produtos ao ambiente.

A pecuária encontra vantagens nas várzeas, pela fartura de pastos nativos de boa qualidade e palatabilidade. Entretanto, o criatório de gado bovino é prejudicado pelo excesso de água, em alguma parte do ano e, muitas vezes, os fazendeiros perdem o gado ou o vendem a preços muito abaixo do mercado, devido às grandes enchentes dos rios que 
inundam até mesmo as restingas e, por não disporem de pastagens na terra firme, para deslocar os rebanhos na época das cheias.

Em alguns locais do Estado, como em Maués e Parintins, o uso do binômio várzea - terra firme, para a criação de gado, é uma prática comum e vem dando bons resultados, uma vez que naqueles municípios, quando o gado é deslocado para o pasto de terra firme, os fazendeiros fazem a suplementação mineral, o que evita a perda excessiva de peso pelos animais. $\mathrm{O}$ gado que mais se adapta às condições de excesso de água, como ocorre nas várzeas, é o bubalino. Todavia, mesmo havendo condições favoráveis nas várzeas para esses animais, o plantel, ao nível de Estado do Amazonas, ainda é pequeno.

\section{Trabalhos de Pesquisa Realizados nas Várzeas do Amazonas}

$\mathrm{O}$ programa de pesquisa da Embrapa, em várzea do Estado do Amazonas é uma continuação dos trabalhos que vinham sendo executado pelo extinto Instituto de Pesquisa e Experimentação Agropecuária da Amazônia Ocidental - IPEAAOc. Através desses trabalhos foram feitas seleções de cultivares, com alta produtividade, bem como definidos a melhor época de plantio, espaçamento, técnicas de consórcio, controle de plantas daninhas e das principais pragas e doenças (Nogueira, 1978; Nogueira, 1981a; Nogueira, 1982; Brandão et al., 1980; Embrater/Embrapa, 1983) para garantir o sucesso do cultivo, melhorar a eficiência de uso da terra e diminuir os custos de produção, para as principais culturas anuais de interesse dos agricultores. Esses trabalhos foram realizados na Estação Experimental do Caldeirão, situada no município de Iranduba, à margem esquerda do Rio Solimões e foram direcionados principalmente para as culturas de milho, arroz, feijão caupi e mandioca.

As tecnologias mais promissoras geradas através desse programa de pesquisa foram testadas, ao nivel de produtor, na década de 80 , por ocasião da execução do Programa de Desenvolvimento Rural Integrado do Estado do Amazonas - PDRI, obtendose resultados animadores.

Os principais resultados já obtidos são descritos a seguir, de acordo com as culturas:

\section{Resultados para Milho}

As pesquisas da Embrapa com milho nas várzeas do Estado do Amazonas foram direcionadas para a obtenção de cultivares que fossem compatíveis com as condições sócioeconômicas dos pequenos produtores da região. Desta forma, buscava-se identificar variedades com produtividade média de grãos superior à obtida no Estado, que era de $1.500 \mathrm{~kg} \cdot \mathrm{ha}^{-1}$; de ciclo precoce, para ser compativel com o período propício de cultivo das várzeas; de porte baixo, para evitar o acamamento; com grãos de boa qualidade para alimentação de pequenos animais; resistente às doenças e pragas que são comuns no Estado; e, de polinização aberta, para permitir ao agricultor usar as sementes no ano seguinte, pois eles têm dificuldades para 
a aquisição de sementes híbridas no mercado local (Xavier \& Sá Sobrinho, 1983; Barreto et al., 1985a, 1985b, 1985c;. Barreto et. al., 1987; Barreto, 1988).

Com as características mencionadas acima foram selecionadas, lançadas e hoje recomendadas, as variedades BR 5102 e BR 5110, com média de $4.500 \mathrm{~kg} \cdot \mathrm{ha}^{-1}$ de grãos (Barreto et al., 1987, Barreto et al., 1998a, Barreto et al., 1998b). Essas variedades podem também ser cultivadas em terra firme, podendo ser obtidos rendimentos de grãos semelhantes aos obtidos nas várzeas, com a correção da acidez e adubação adequada do solo (Cravo \& Smyth, 1991b).

\section{Resultados para Arroz}

As pesquisas com arroz também visavam selecionar variedades mais apropriadas às condições de várzea do Estado do Amazonas, cuja produtividade média estadual é inferior a $2.000 \mathrm{~kg} \cdot \mathrm{ha}^{-1}$ de grãos por safra. Dentre as variedades recomendadas para os produtores destacaram-se a BR-1, a Ajuricaba e outras ainda em fase de melhoramento, com produtividade acima de $4.500 \mathrm{~kg} \cdot \mathrm{ha}^{-1} \mathrm{e}$ com grãos de excelente qualidade e rendimento de engenho (Rangel, 1977; Martins \& Rangel, 1981; Embrapa, 1981; 1982; 1984; Martins \& Galvão, 1982; Galvão \& Martins, 1988). Também foram realizadas pesquisas sobre irrigação da cultura do arroz cujos resultados mostraram que, devido a presença marcante de silte nos solos de várzea do Rio Solimões, a capacidade de retenção da água é baixa, necessitando de alto custo de energia para a irrigação. Desta forma é preferível o cultivo no sistema de sequeiro, aproveitando a umidade natural do solo (Cravo \& Smyth, 1991a).

\section{Resultados para Feijão Caupi}

As pesquisas com feijão caupi têm, entre outras finalidade, a de produzir grãos dessa leguminosa para substituir o feijão Phaseolus que, nas condições de várzeas úmidas, tem problemas sério devido à doença denominada de "mela" (Nogueira, 1981b;). O feijão caupi, nas condições de várzea do Amazonas, tem tido bom comportamento produtivo, atingindo produtividade acima de $1.000 \mathrm{~kg} \cdot \mathrm{ha}^{-1}$ de grãos (Nogueira \& Carvalho, 1978). Possivelmente o bom comportamento dessa leguminosa nas várzeas esteja relacionado com sua exigência em fósforo (Smyth \& Cravo, 1990) e cálcio (Smyth \& Cravo, 1992), cujos teores são elevados na maioria dos solos das várzeas do Amazonas.

As cultivares disponíveis para recomendação são a Manaus e a BR8 Caldeirão (Nogueira, 1981c; Dias, 1986), em substituição à IPEAN V-69 (Nogueira \& Martins, 1980), há muito tempo recomendada para a região como um todo. Essas duas cultivares também comportam-se muito bem no ecossistema de terra firme, podendo ser cultivadas tanto no sistema de monocultivo, como em rotação com outras culturas, principalmente com as gramíneas ou, no sistema de consórcio com milho e mandioca (Embrater/ Embrapa, 1983). É também um excelente componente inicial de 
sistemas agroflorestais pois, além dos grãos, fornece nitrogênio fixado do ar, aos demais componentes do sistema, representando uma economia na compra desse insumo (Cravo \& Smyth, , 1991b).

\section{Resultados para Mandioca}

A cultura da mandioca tem se mostrado uma alternativa, econômicosocial, muito importante para utilização das várzeas do Estado do Amazonas. Nesse ecossistema, as cultivares selecionadas atingem a maturação aos oito meses, permitindo a colheita antes do novo período de enchente. A produtividade alcançada com as cultivares selecionadas está acima das 19 tha $^{-1}$ de raizes, em áreas novas. Nas áreas anteriormente cultivadas com mandioca e, devido a elevada umidade do solo, ocorre podridão radicular causada pelo fungo Phythophthora ssp (Xavier et al, 1993a; 1993b; Xavier, 1989), diminuindo consideravelmente o rendimento produtivo de raizes da cultura.

Trabalhos realizados para tentar contornar o problema, mostraram a diminuição da quantidade de raizes podres, pelo uso de camalhões feitos com microtrator (Tab. 6). Mesmo com essa prática, a produtividade obtida representou apenas $50 \%$ da que se obtém em áreas recém desbravadas, sem uso de camalhões, uma vez que $a$ área experimental encontrava-se sob pressão de inóculo.

Outro trabalho direcionado para diminuir a incidência da podridão radicular da mandioca é o uso de cultivos em rotação com feijão caupi, milho e arroz. Os resultados são muito promissores esperando-se, para um futuro próximo, informações mais seguras sobre essas práticas de cultivo.

Atualmente são recomendadas para o ecossistema de várzea do Amazonas as cultivares "Zolhudinha", "Mãe Joana" e "Amazonas EMBRAPA-8", todas com produtividade de raizes acima de $19 \mathrm{tha}^{-1} \mathrm{e}$ com tolerância à principal doença desse ambiente, que é a podridão radicular, causada pelo fungo Phythophthora ssp. (Xavier, 1989; Xavier et al., 1991; 1993a; 1993b).

Os novos passos da pesquisa com mandioca serão em direção à seleção de cultivares de polpa amarela e branca, com alto rendimento de farinha e,

Tabela 6. Efeito do preparo do solo sobre a produtividade e incidència da podridão em raizes de mandioca cultivada em várzea do Rio Solimões.

\begin{tabular}{lcc}
\hline Tratamento & Produtividade & Raízes podres \\
\hline & t.ha-1 & $\%$ \\
Sem preparo do solo & $1,3 \mathrm{~b}$ & $68,5 \mathrm{a}$ \\
Com araçăo e gradagem & $3,3 \mathrm{~b}$ & $53,4 \mathrm{~b}$ \\
Camalhăo/Manual & $6,6 \mathrm{~b}$ & $45,0 \mathrm{~b}$ \\
Camalhăo/ Microtrator & $10,5 \mathrm{a}$ & $36,8 \mathrm{~b}$ \\
\hline
\end{tabular}


macaxeira (mandioca mansa ou de mesa). A iniciativa de selecionar macaxeira tem a finalidade de fornecer materiais de alta produção e resistentes às doenças, principalmente para áreas próximas aos grandes centros consumidores do Estado, pois a macaxeira representa uma boa fonte de renda para os agricultores, além de ser um componente importante da dieta alimentar do agricultor e de seus animais. Além dessas ações, serão pesquisados métodos de propagação rápida e práticas de adubação mineral e orgânica, com a finalidade de aumentar a produtividade da cultura.

\section{Outras Atividades de Pesquisa}

Além dos trabalhos relatados anteriormente, outras atividades de pesquisa foram levadas a efeito nas várzeas do Rio Solimões, especialmente para testar as respostas de arroz e milho à adubação nitrogenada e, às perdas de nitrogênio para o subsolo. Os resultados podem ser encontrados em Melgar et al. (1992).

\section{Uso Potencial das Várzeas no Amazonas}

\section{Sugestões de Uso das Várzeas do}

Amazonas, em função da localização, em relação aos centros consumidores

Resolvidos os principais problemas das várzeas, tais como: a) eliminação das limitações nutricionais dos solos, principalmente de nitrogênio; b) seleção de variedades/ cultivares de plantas de alta produtividade e com resistência ou tolerância a pragas e doenças; c) compatibilização do ciclo das culturas e/ou atividades a serem desenvolvidas nas várzeas, com os periodos de inundação e precipitação pluviométrica; d) controle de plantas daninhas nas plantações; e) intensificação dos trabalhos de pesquisa em olericultura, fruticultura (para oferecer novas alternativas aos produtores), silvicultura (buscando alternativas para reposição dos estoques madeireiros naturais, intensivamente explorados nas várzeas); $\mathrm{e}, \mathrm{f}$ ) resolução dos problemas de ordem estruturais, como a garantia de posse da terra, a assistência técnica e creditícia, esse ecossistema pode se tornar o principal fornecedor de fibras e proteína animal e vegetal, para abastecer os principais núcleos populacionais do Estado.

Por outro lado, considerando-se as caracteristicas da região, cujo principal meio de transporte é o fluvial, a utilização das várzeas deve ser planejada em função da facilidade de escoamento da produção para os mercados mais próximos, tendo-se em mente a perecibilidade dos produtos. Desta forma, e considerando-se os aspectos apontados acima, sugere-se como uso mais adequado para as várzeas, as seguintes atividades:

\section{Conclusões}

Com base no exposto e considerando as principais características das várzeas que ocorrem no Estado do Amazonas chegou-se as seguintes conclusões:

A qualidade das águas que inundam as várzeas exercem influência nas caracteristicas químicas 
dos solos e, consequentemente, na produtividade das culturas:

O cultivo contínuo das áreas de várzea, sem inundação e sem a devida adubação nitrogenada, provoca a diminuição da produtividade das culturas;

Os principais fatores que limitam o uso das várzeas são: o regime de enchente, o excesso de umidade, a infestação por plantas daninhas e a distância dos mercados consumidores; Há necessidade de intensificação dos trabalhos de pesquisa, nas áreas de várzeas, em busca de variedades de plantas precoces, adaptáveis às condições de umidade do solo, resistentes ou tolerantes a doenças e pragas e, com alta produtividade a fim de serem exploradas no curto periodo

Tabela 7. Sugestòes de uso das várzeas, em função da distância dos centros consumidores

Para áreas próximas

. Olerícolas de modo geral;

-Feijão caupi;

Milho verde;

- Mandioca (brava e mansa)

- Fruticultura (Mamäo, Maracujá, Banana, Açai, etc.):

- Criação de pequenos animais (principalmente porcos e aves, aproveitando os restos de alimentos provenientedas atividades agricolas);

- Gado bovino e bubalino para leite (com a implantação de pequenos pastos de "refúgio" naterrafirme, para a retirada e alimentação do gado no periodo das cheias); e,

- Pesca nos lagos, com embarcaçöes providasdecâmarasfrigorificasou do tipo "geleira".
„Fibras (juta e malva);

- Mandiocabravaparaproduçãodefarinhae fécula;

- Reflorestamentocomá rvoresmadeireiras nativas (Sumaúma, Açacu, Virola, Andiroba, etc.) e outras adaptáveis às condiçôesdas várzeas, as quais tenham rápido crescimento e mercado garantido;

- Gráos (Milho, Arroz, Feijão Caupi, etc.) nos períodos mais adequados para seus cultivos;

- Gado de corte bovino, utilizando-se os pastos nativos das restingase, com a abertura de campos de "refúgio" na terrafirme, para a manutenção do rebanho, em regime semi intensivo, durante o periodo das cheias.

- Gado de corte bubalino, utilizando os pastos das várzeas baixas, inadequados para o gado bovino, com a abertura de campo de "refúgio" na terra firme, para a manutenção do rebanho, emregimesemiintensivo, duranteoperíodo das cheias.

- Pesca nos lagos, com embarcações providas de câmaras frigorificas ou do tipo "geleira".

- Implantação de Reservas Biológicas Extrativistas 
em que as várzeas não se encontram inundadas; e,

As várzeas se revelam como um ecossistema com alto potencial para produção de alimentos e fibras, para suprir não só os mercados regionais mas, até mesmo, para exportação. Entretanto, no planejamento para sua exploração, devem ser considerados o regime de enchente dos rios, a perecibilidade dos produtos e a distância dos locais de produção em relação aos mercados consumidores.

\section{Bibliografia citada}

Brasil, 1979. Ministério da Agricultura, Secretaria Nacional de Planejamento Agricola. Aptidão agrícola das terras do Amazonas. Brasilia, BINAGRI. (BINAGRI. Estudos básicos para o planejamento agrícola, Aptidão agrícola das terras, 12) 142p.

Barreto, J.F., 1988. Melhoramento da população de milho CMS-19 para o estado do Amazonas. Manaus: Embrapa-UEPAE Manaus. (Embrapa-UEPAE Manaus. Pesquisa em Andamento, 81) 4p.

Barreto, J.F.; Sá Sobrinho, A.F.; Sá, A.C.R., 1985a. Seleção massal da população de milho CMS-11 nova opção de cultivar para o estado do Amazonas. Manaus: EmbrapaUEPAE Manaus. (Embrapa-UEPAE Manaus. Pesquisa em Andamento, 66), 3p.

Barreto, J.F.; Sá Sobrinho, A.F.; Ferreira, A.F., 1985b. Avaliação de cultivares milho para o estado do Amazonas - ensaio regional de milho 1983/84. Manaus: Embrapa-UEPAE Manaus. (Embrapa-UEPAE Manaus. Pesquisa em Andamento, 68), 5p.

Barreto, J.F.; Sá Sobrinho, A.F.; Sá, A.C.R.., 1985c. Avaliação de híbridos intervarietais e variedade de milho em várzea do Amazonas. Manaus: Embrapa-UEPAE Manaus. (Embrapa-UEPAE Manaus. Pesquisa em Andamento, 69), 3p.

Barreto, J.F.; Carneiro, J. S.; Correa, J.C.,
1987. Ensaio de avaliação de cultivares de milho. Manaus: Embrapa-UEPAE Manaus. (Embrapa-PNP Milho. Projeto 003800737, Relatório Final), 26p.

Barreto, J.F.; Martins, G.C.; Xavier, J.J.B.N.; Dias, M.C.; Silva, J.P. 1998. Avaliação de cultivares de milho no Amazonas. Manaus: (EmbrapaCPAA. Pesquisa em Andamento, 50).

Barreto, J.F.; Sá Sobrinho, A.F.; Gama, E.E.G.; Xavier, J.J.B.N.; Cunha R.N.V., 1998. BR-5110 - Solimões: milho de várzea do Amazonas. Manaus: Embrapa-CPAA, (Embrapa-CPAA. Comunicado Técnico, 9), 3p.

Brandão, J. N.; Nogueira, O.L.; Rangel, P.H.N.; Martins, C. S.; Carneiro, J. S., 1980. Sistemas de produção de feijão caupi, milho e arroz em várzea (recomendações da pesquisa). Manaus: Embrapa-UEPAE Manaus, (EmbrapaUEPAE Manaus. Circular Técnica, 01). $16 \mathrm{p}$.

Cochrane, T.T.; Sánchez, P.A., 1982. Land resources, soil and their management in the Amazon region: a state of knowledge report. In: Hecht, S.B. (ed.) Amazônia - agriculture and land use research. Centro Internacional de Agricultura Tropical CIAT. Cali, Colômbia, p. 137-209.

Correa, J.C.; Bastos, J.B., 1982. Os solos das várzeas do Paraná dos Ramos (municipio de Barreirinha - Amazonas) e sua fertilidade. Manaus. Embrapa - UEPAE de Manaus. (Embrapa - UEPAE de Manaus, Boletim de Pesquisa 1), 26p.

Cravo, M.S.; Smyth, T.J., 1991a. Manejo de solo de várzea para arroz irrigado na Amazônia brasileira central. In: Smyth, T.J.; Raun, W.R.; Bertsch, F. Manejo de suelos tropicales en Latinoamerica. North Carolina State University. Raleig, N.C., p.191-195.

Cravo, M.S.; Smyth, T.J., 1991b. Sistema de cultivo contínuo com altos insumos na Amazônia brasileira. In: Smyth, T.J.; Raun, W.R.; Bertsch, F. (eds.) Manejo de suelos tropicales en Latinoamerica. North Carolina State University, Raleigh, NC, p. 144-156.

Dias, M.C., 1986. BR-8 Caldeirão - Nova cultivar de feijão caupi para o Estado do 
Amazonas. Manaus, Embrapa-UEPAE de Manaus. (Embrapa-UEPAE de Manaus. Comunicado Técnico, $\left.\mathrm{n}^{\circ} 45\right), 4 \mathrm{p}$.

Embrapa - Empresa Brasileira de Pesquisa Agropecuária. 1981. Relatório Técnico Anual da Unidade de Execução de Pesquisa de Âmbito Estadual de Manaus - 1980. Manaus, Embrapa. UEPAE de Manaus, 202p.

Embrapa - Empresa Brasileira de Pesquisa Agropecuária. 1982. Relatório Técnico Anual da Unidade de Execução de Pesquisa de Âmbito Estadual de Manaus - 1981. Manaus, Embrapa. UEPAE de Manaus. $377 \mathrm{p}$.

Embrapa - Empresa Brasileira de Pesquisa Agropecuária. 1984. Relatório Técnico Bienal da Unidade de Execução de Pesquisa de Âmbito Estadual de Manaus - 1982/1983. Manaus, Embrapa. UEPAE de Manaus. 360p.

Embrater/Embrapa, 1983. Sistema de produçào para arroz, feijão, milho e mandioca para o Estado do Amazonas. Manaus. (Sistema de Produção, Boletim Técnico $n^{2} 2$ 2), 65p.

Galvão, E.U.P.; Martins, G.C. 1988. Ajuricaba nova cultivar de arroz para várzea. Manaus: Embrapa-UEPAE Manaus. (EmbrapaUEPAE Manaus. Comunicado Técnico, 46), 3p.

Martins, G.C.; Galvão, E.U.P. 1982. Avaliação de germoplasma de arroz em condições de várzea. Manaus: Embrapa-UEPAE Manaus. (Embrapa-UEPAE Manaus. Pesquisa em Andamento, 37), 2p.

Martins, G.C.; Rangel, P.H.N. 1981. Cultura do arroz para as várzeas do estado do Amazonas. Manaus: Embrapa-UEPAE Manaus. (Embrapa-UEPAE Manaus, Comunicado Técnico, 18), 5p.

Nogueira, O.L. 1978, Espaçamento de feijão caupi em área de várzea. Manaus: EmbrapaUEPAE Manaus. (Embrapa-UEPAE Manaus. Comunicado Técnico, 01), 8p.

Nogueira, O.L. 1981a. Rotação de feijão com milho e arroz em área de várzea. Manaus: EmbrapaUEPAE Manaus. (Embrapa-UEPAE Manaus. Comunicado Técnico, 25), 3p.

Nogueira, O.L. 1981b. Cultura do feijão caupi no estado do Amazonas. Manaus: EmbrapaUEPAE Manaus. (Embrapa-UEPAE Manaus. Circular Técnica, 04), 2lp.

Nogueira, O.L. 1981c. "Manaus" nova cultivar de feijão caupi para o Amazonas. Manaus: Embrapa-UEPAE Manaus. (EmbrapaUEPAE Manaus. Comunicado Técnico, 26), $3 p$.

Nogueira, O.L. 1982. Consorciaçào de milho e feijão em várzea do estado do Amazonas. Manaus: Embrapa-UEPAE Manaus. (Embrapa-UEPAE Manaus. Circular Técnica, 05), 18p.

Nogueira, O.L.; Carvalho, J.M.F. 1978. Avaliação de cultivares de feijão caupi nas várzeas do Rio Solimões. Manaus: Embrapa-UEPAE Manaus. (Embrapa-UEPAE Manaus. Comunicado Técnico, 03), 10p.

Nogueira, O.L.; Martins, C. S. 1980. "IPEAN V-69" cultivar de feijào caupi recomendada para o estado do Amazonas. Manaus: EmbrapaUEPAE Manaus, (Embrapa-UEPAE Manaus. Comunicado Técnico, 13), 3p.

Melgar, R.J.; Smyth, T.J.; Sánchez, P.A.; Cravo, M.S. 1992. Fertilizer nitrogen movement in a Central Amazon Oxisol and Entisol cropped to corn. Fertilizer Research, 31;241-252.

Rangel, P.H.N. 1977. Relatório de atividades técnicas, periodo: julho de 1975 a dezembro de 1977. Manaus, EmbrapaUEPAE de Manaus.

Sioli, H. 1957. Valores de $\mathrm{pH}$ de águas amazônicas. Bol. do Museu Paraense Emilio Goeldi. Geologia, (1):1-37

Smyth, T.J.; Cravo, M.S. 1990. Phosphorus management for continuous corn-cowpea production in a Brazilian Amazon Oxisol. Agron. J. 82: 305-309.

Smyth, T.J.; Cravo, M.S. 1992. Aluminum and calcium constraints to continuous crop production in a Brazilian Amazon Oxisol. Agron. J. 84:843-850.

Xavier, J.J.B.N. 1989, Adaptaçào de cultivares de mandioca para a Região Amazônica. Manaus: Embrapa-UEPAE Manaus, 1980/1989. (Embrapa-PNP Mandioca. Relatório de Projeto009800962, em Andamento), 15p. 
Xavier, J.J.B.N.; Sá Sobrinho, A.F. 1983. Avaliação preliminar de cultivares de milho no município de Parintins em área de várzea. Manaus: Embrapa-UEPAE Manaus. (Embrapa-UEPAE Manaus. Pesquisa em Andamento, 46), 3p.

Xavicr, J.J.B.N.; Cruz, L.A.A.; Labenny, A.; Lozano, J.C; Fukuda, C. 1991. Controle integrado de podridào de mandioca na zona de várzea da rcgião amazonica. In: Congresso Brasilciro de Mandioca, 6., Programas e resumos, Londrina.

Xavier, J.J.B.N.; Santos, A.F.; Dias, M.C.; Lozano, J.C; Fukuda, C. 1993a. Controle da podridào das raízes da mandioca, causada por Phythophthora. Fitopatologia Brasileira, 18 ( suplemento).

Xavier, J.J.B.N.; Santos, A.F.; Dias, M.C.; Lozano, J.C; Fukuda, C. 1993b. Avaliação dc resistência à podridão radicular em mandioca. Fitopatologia Brasileira, 18 (suplemento).

Aceito para publicação em 12/07/2002. 